\title{
Processes on Paper: Writing Procedures as Non-Material Research Devices
}

\section{Christoph Hoffmann}

University of Lucerne

E-mail: christoph.hoffmann@unilu.ch

\section{Argument}

The paper focuses on the instrumentality of writing in the context of scientific research. It is suggested that the tool-character of writing is related to specific writing procedures, such as the list. These procedures can vary in their degree of complexity and often follow rules that are not codified. In any case, writing procedures can be characterized as non-material devices of "concretion." Two examples from the notebooks of the physicist and philosopher of science, Ernst Mach (1838-1916), will help to develop the notion of writing procedures. Typical for Mach's use of his notebooks, they highlight the effects of writing in the context of reasoning and reflecting.

\section{Notebooks as Source Material}

When some decades ago historians of science began exploring the domain of scientific practice, this resulted if nothing else in a turn towards new practices of inquiry. Going to the library and studying books and journals alone was no longer sufficient for scholars who tried to go beyond the textbook account of scientific discovery. Following the traces of scientists in the laboratory or in the field - with the now-classic phrase of Frederic Holmes, recovering "investigative pathways" (Holmes 2004) - rather demanded archival work and relentless "close reading" of research documents. As a consequence a very special type of material attracted attention: small slips covered with scribbles and huge volumes of records, bundles of letters, and series of notebooks, printed forms, drafts, tables, graphs, drawings: in short, bulks of papers, which form the primary output and residuum of scientific activities. ${ }^{1}$

Personal papers and institutional records contain rich information on the everyday work of scientists, but like historical sources in general, they cannot offer direct access to past activities. Of course, history has developed a sophisticated critical apparatus

\footnotetext{
${ }^{1}$ Lab ethnographers shared such experiences. Bruno Latour's original surprise at the pervasiveness of graphical and writing processes in research is well known (Latour 1990, 21f). As a consequence the analysis of "paperwork" became one of the main subjects of science studies.
} 
to bridge the gap between the remnants at hand and the events that once took place. Nevertheless, it was no accident that one of the historians who contributed most to the development of this historical method, Johann Gustav Droysen, once warned his readers that not the "centuries and millennia of the past" form the object of history, but "a presence of materials" (Droysen [1857] 1977, 9), which above all is scattered "in overwhelming masses of details" (ibid., 101). Scholars working with the remnants of scientific activities are quite familiar with this consideration. Notebooks of researchers in particular provide an instructive example. Often considered an immediate compendium of observations and an intimate site of reasoning, they promise privileged access to a scientist's original attention, preliminary ideas, personal speculations, and, in general, to the off-record sphere of scientific work (cf. Holmes, Renn, Rheinberger 2003). Yet almost everyone who examines research notebooks shares the experience of how incommensurable, fragmentary, crude, puzzling, and thus hard to conceive such material is. Apparently research notebooks do not at all permit a direct look into the researcher's mind or - through his or her eyes at the course of events at the research site. Only when contextualized by additional sources and supplementary assumptions does the content of research notebooks become intelligible.

Looked upon from a slightly different angle, these measures of contextualization recall the fact that research notebooks, strictly speaking, do not contain thought processes, experimental operations, observations, or measurements, but simply: writeups. In addition to the ambiguities of language, the process of writing adds a separate challenge to the reconstruction of past activities. Writing up must be acknowledged as a source of distortion for what is written up. Yet to speak of a distortion is only justified insofar as one argues from the viewpoint of a historian of science who evaluates written materials as sources of events that have taken place in the real world or in the researcher's mind. This paper, by contrast, proposes the opposite viewpoint. Whatever might have happened in reality or in the mind has passed through the process of writing. Accordingly, from this perspective, the first objects of inquiry are inscriptions. The shift is as simple as it is fundamental; research notebooks can be interrogated either as sources for research operations and concept formation or as sources for writing processes. Yet the alternative is not a complete one. Writing must rather be considered an instrument of research itself, structuring practical tinkering, organizing the outcomes, and intervening in the more abstract work of reasoning and reflecting. In other words, with the focus on processes of writing, a critical factor of the research practice shall be analyzed.

Take, for example, the list. As Jack Goody has emphasized,

The list relies on discontinuity rather than continuity; it depends on physical placement, on location; it can be read in different directions, both sideways and downwards, up and down, as well as left and right; it has a clear-cut beginning and a precise end, that is, a 
boundary, an edge, like a piece of cloth. Most importantly it encourages the ordering of items, by number, by initial sound, by category, etc. (Goody 1977, 81)

In other words, a list represents an organizational tool, which provides ground for multifarious analytical operations. From this point of view "list" is the name of a rule of production or procedure by which words, numbers, and signs are processed that represent objects, ideas, events, actions, etc. In the following section I will suggest that, in fact, the instrumentality of writing must be attributed to and located in procedures of writing. For now, Goody's commentary on the list teaches us that the study of such procedures is dependent on a certain mode of inspection. Attention must shift from reading the inscriptions (focusing on their meaning) to the question of how these inscriptions have been produced. For example, a post-mortem record may be studied with respect to the findings noted and the final diagnosis. A post-mortem record may also be studied with respect to the rules of recording and the particular scene of writing in the dissection room (cf. Hoffmann 2008; for the notion "writing scene," see Campe 1991). In the latter case, aspects other than the meaning of the words attract attention. A striking neatness of the handwriting, for instance, might indicate that the record was either dictated or produced afterward with the help of notes or from memory.

The study of writing procedures implies similar challenges, such as exploring the written content. Once again the material - the record, the journal, the research notebook, etc. - is taken as a source for something clearly absent. The sheets of paper only preserve the remnants of writing processes, and many of the circumstances that affected and shaped the visible traces cannot be determined from the material basis. Returning to the example of the post-mortem record: whether a neatly written record was dictated or produced afterwards cannot be known without information on the organization of work in the particular autopsy room. The shift from retrieving written materials as sources for events in the real world or in the mind, to interrogating written materials as traces of writing procedures is, therefore, not equivalent to a shift from a more to a less problematic type of inquiry. The aim of this paper is instead to highlight an aspect usually ignored in the evaluation of records, drafts, tables, files, lists, or notes, not just within the context of the history of science.

In the following section I will develop the notion of writing procedures and the particular kind of instrumentality that characterizes such practices. Thereafter, I will introduce the sample case of my argument: the notebooks of the physicist and philosopher Ernst Mach (1838-1916). Some remarks on the workspace in which they were embedded will highlight the prominent role of these notebooks in Mach's research practice. For practically the entire span of Mach's career, the notebooks marked the site where daily work and scientific reasoning (sometimes interrupted by private matters) were mingled, planned, organized, or reworked. Then, two examples from Mach's notebooks shall refine our discussion of writing procedures. Here, the focus is on the use of writing in the context of reasoning and reflecting. The first example illustrates the role of lists in shaping the topic of a lecture. The second example addresses 
the instrumentality of writing in structuring a research question and is related to an iterative procedure of notating. Finally, I elaborate the problem of generalization and the probable contribution of studies of this kind toward expanding the notion of writing.

\section{Writing Procedures}

Studies on the role of writing in scientific research usually take one of two routes. One - following Bruno Latour's lead - focuses on "paperwork" as a mode of accumulating knowledge, while the second, which can be identified with Ursula Klein's notion of "paper tools," tries to discern the particular contribution of writing to the emergence and reworking of research objects. In the following, I first summarize Latour's and Klein's approaches and then, more closely aligning myself with Klein's perspective, develop a refined understanding of writing procedures as an instrument of research. "Paperwork" in Latour's sense comprises the accumulation, recombination, and superimposition of written documents, drawings, and all sorts of graphic traces (Latour 1990, 52-60). In Latour's own words, paperwork is almost identical to "paper shuffling," and the central phenomenon of interest in his eyes is the "essential power" connected to this kind of activity (ibid., 55). "Paperwork" is thus another word for the several ways science (but not only science) relies on work with pieces of paper. Accordingly, what is emphasized with reference to the word paper is a particular system of informational storage and circulation (generally speaking). In contrast, Ursula Klein refers to a practice of forming scientific objects. She characterizes as "paper tools" so called "Berzelian formulas" which have been used in organic chemistry since the 1830s "for the investigation of the chemical reactions and the constitution of organic substances" (Klein 2001, 290). Klein thus does not stress work with paper, but the work done on paper, namely the elaboration and transformation of these formulas. In this respect, the "sign system" "Berzelian formula" plays the role of tool in the "paper tool" (ibid., 292), whereas "paper" mainly represents one of the material requirements for the application of this tool.

Roughly speaking, "paperwork" and "paper tools" include two approaches to the paper domain of scientific practice. The first approach concerns the processing of papers and highlights the persuasive effects and the increase of knowledge related to the arrangement and display of paper materials (examples include the usage of index cards in psychiatric research: Weber and Engstrom 1997 and Engstrom 2003, 137-42; and the collection of paper clippings: te Heesen 2006). In contrast, the second approach deals with the processes on paper and highlights their effects on the investigation of scientific objects (cf. Barberousse 2003 and Wickman 2010 on laboratory notes; for similar approaches with respect to drawing practices, see Galison 2000; Kaiser 2005; Nasim 2010). With this in mind, the discussion of writing procedures may be aligned with Klein's perspective. It appears, however, that the productive character of her "paper 
tools" seems far more linked to the symbolic operations that take place in the gesture of writing than to the actual process of writing and the resulting order on the surface of the paper. Although at one point Klein emphasizes that the "graphic suggestiveness and maneuverability" of the Berzelian formulas and the "actual manipulations on paper" were crucial for deriving the "new concept of substitution" in chemistry (Klein 2001, 289), one may suspect that this advance was primarily connected to the rules applied in constructing and transforming the terms. Pointing to the same conclusion is the fact that the usefulness of Berzelian formulas primarily relates to "compositional syntax and semantics," i.e. to the symbolic operations that they render possible (ibid., 292).

The question then arises as to whether the tool-character of writing can be linked more directly to the writing process. As a first step in this direction, it is necessary to accept that paper and pencil are indeed trivial, simple, not especially elaborated "technical objects" for dealing with "epistemic things" (cf. on these notions, see Rheinberger 1997, 28-31). In comparison to a mirror galvanometer or an ultra centrifuge (not to mention sequence automata or radio detectors), paper and pencil alone are hopelessly underdetermined devices of research. They only gain specificity in the particular course of their use. In this respect, it is important to distinguish between the "mere" gesture of writing and the procedure of writing. The former (once learned in school) covers the complex interplay of hand, writing instrument, and writing surface, which begins the very moment we mark characters on the surface of a sheet of paper. The latter signifies the schematic approach - e.g. the scheme "list" - realized in the gesture of writing.

A procedure is a non-material device. Of course, materials (like paper and pen) are required for implementing a procedure, but at its core, it consists of a framework for going about a task (on procedures in scientific research, see Gooding 1992); very much in contrast to Gooding, I do not presuppose that procedures usually are "unpremeditated" and "preverbal" (ibid., 52-53). Procedures are characterized by a sequence of actions that unfolds along the time axis and cannot be easily inverted. In general, two types of procedures may be differentiated. The first is goal-oriented, i.e. the sequence of actions is determined in advance by a certain aim (a famous example from engineering is the "Haber-Bosch-process" for producing ammonia). The second type of procedure is process-oriented, i.e. the sequence of actions frames an open process with an indeterminate result. The legal system offers a good example in this respect. As Niklas Luhmann emphasized, a procedure (in German Verfahren), unlike a "ritual," is associated with a "true event," that is, in the process a "reorientation of expectation" may take place (Luhmann [1975] 1983, 37).

Writing procedures fall into the second class of process-oriented procedures. Like legal procedures, they merely offer a framework for going about an action, ${ }^{2}$ but in contrast to legal procedures, writing procedures are less formal and codified.

\footnotetext{
${ }^{2}$ In contrast the "mere" gesture of writing resembles a goal-oriented procedure that we once automated in writing lessons.
} 
Customarily, writing procedures are rarely spelled out (they are simply learned) and are related to the context variable (for example, a shopping list and a checklist represent very different realizations of the procedure list with respect to structure, appearance, and purpose); the exact writing procedure only takes shape as one applies it. ${ }^{3}$ This comports well with an idea in Martin Heidegger's essay "The Age of the World Picture" (1938). Heidegger argued that one recognizes "research" as the basis of modern science by the bracketing of "some realm of beings in nature" as a domain or object of inquiry (Heidegger [1938] 2009, 209; cf. Rheinberger [2007] 2010, 42-46). Within this framework, the procedure performs the critical role of translating the prospect of research into a detailed experience of the outlined object. "Science becomes research through the projection and its securement in the rigor of procession. Projection and rigor, however, first develop into what they are in procedure" (Heidegger [1938] 2009, 211; translation slightly revised). ${ }^{4}$ Heidegger added that the course of inquiry undergoes a permanent reorientation through research. "In these processes, the procedure of a science is encircled by its own results. More and more, the procedure adapts itself to the possibilities of procession that it itself opens up" (ibid., 214; translation slightly revised). ${ }^{5}$

The last point highlights the most striking aspect in Heidegger's notion of procedure. Unlike a concept or a (textbook) method whose purpose consists in neglecting and, ultimately, in transcending the fuzzy details of research practice, a procedure provokes and guides the exploration of the specific object of inquiry. From this point of view, procedures do not (so to speak) mechanically reveal the respective objects of knowledge, already delineated and fully comprehended, but rather help to shape experiences, in the course of which the object of research - continuously accompanied by readjustments to the procedure - gradually emerges. Taken altogether in Heidegger's sense, a scientific procedure primarily represents a means of concretion. Accordingly, writing procedures might be best understood as flexible sets - with certain limitations - that help structure the processed issue and enable further experiences.

A final point must be mentioned. Considering the most ubiquitous writing procedures in science - record, table, and list - it could appear that writing mainly

\footnotetext{
${ }^{3}$ The same is true for many laboratory sciences, which rely on standard procedures and prefabricated kits. As a rule, these tools must be adapted to the challenges of a particular experiment (see for example Lynch 1985, 64-68).

4 "Die Wissenschaft wird zur Forschung durch den Entwurf und durch die Sicherung desselben in der Strenge des Vorgehens. Entwurf und Strenge aber entfalten sich erst zu dem, was sie sind, im Verfahren” (Heidegger [1938] 1977, 73). The usual translation of Verfahren by "method" blurs the notable difference in German between Verfahren and Methode. The former belongs to the practical sphere of going about a task, whereas the latter signifies much more an idealized, abstracted way of doing. From Heidegger's argument, it is obvious that he very intentionally decided on the notion Verfahren to emphasize the flexible, provisional picture of the research process.

5 “In diesen Vorgängen wird das Verfahren der Wissenschaft durch ihre Ergebnisse eingekreist. Das Verfahren richtet sich immer mehr auf die durch es selbst eröffneten Möglichkeiten des Vorgehens ein” (Heidegger [1938] 1977, 77).
} 
becomes instrumental by creating spatial arrangements. Along this line, Sybille Krämer relates the productive potential of writing in research to effects of "notational iconicity" which figures in with the visual inspection of the written product (Krämer 2005; Ursula Klein's case of the Berzelian formulas would fit in here). Hans-Jörg Rheinberger has also emphasized the fact that in recording an experiment, for instance, a four-dimensional event in space and time is translated into a notational sequence on a two-dimensional surface (Rheinberger 2003, 625). This causes problems of synchronicity and clearly does not work without reductions (Welfele 1998-1999, 32), but at the same time, the record gives the experiment a permanent, organized shape, which is the prerequisite for any further evaluation. Nevertheless, writing also possesses a temporal dimension. The spatial arrangement of inscriptions on the writing surface, which is the final result of a writing procedure, depends on a sequence of actions that unfolds in time. Usually this relation to time merely represents a constraint in the procedure's application. This is the case, for example, when complex and transient phenomena are to be noted down for an observational record. But as we will see later, in some cases the writing procedure seems to rely more intimately on a genuine "sequentiality" or temporal arrangement.

In summary, it has been suggested that studying the instrumentality of writing requires a focus on the processes on paper. One example for such processes can be found in the usage of Berzelian formulas in chemistry. However, the instrumentality of this "paper tool" is very much bound to the symbolic operations enabled by the sign system "Berzelian formulas." In this respect, it has been argued that the instrumentality of writing can be linked more closely to the writing process itself, by considering writing in terms of its procedures. A writing procedure is defined as a sequence of actions, flexible within certain tolerances, that results in a graphical arrangement of written traces. Such writing procedures are process-oriented; they do not determine a certain result, but offer a framework for the concretion of "epistemic things." Writing procedures usually remain implicit, although the sequence of actions of some may be codified. Furthermore, a particular writing procedure is open to a broad variety of purposes, depending on the context of usage. Lastly, writing procedures are very often highly individual; this primarily hinders the reconstruction of the procedure in detail. With respect to the crucial point of my argument - that writing procedures productively intervene in the development and reworking of phenomena and ideas - two effects must be considered: first, the spatial arrangements created by writing procedures and, second, the temporal arrangements that certain writing procedures embody.

\section{Two Writing Desks}

Before we start with the discussion of the examples from Ernst Mach's notebooks, a glimpse at Mach's workspaces will provide some general information on the function of note-taking in his research practice (cf. Hoffmann 2003 and 2010). The Mach 
papers include 53 notebooks spanning the time from the early 1870 s to the year 1910 . Mach started keeping a notebook shortly after he became the director of the Physics Institute of the Charles University in Prague in 1867. He continued with this practice when he took over the chair for the history and theory of the inductive sciences at the University of Vienna in 1895 and eventually stopped using notebooks six years before his death. The last, almost illegible notes document that his precarious health prevented him from writing by hand anymore. Usually Mach preferred notebooks with a size of about $20 \mathrm{~cm}$ by $13 \mathrm{~cm}$, bound in firm cardboard, the number of sheets varying from 60 to 180 . In the majority $(3: 1)$, the pages were unlined. Occasionally glued to the inside cover are small labels listing the name and address of the stationery shops where Mach bought his notebooks. Some additional columns for reordering reveal that he could select from a range of prefabricated items. His favorite writing utensil was the pencil. Sometimes Mach used a colored pencil (blue and red) and ink.

In general, Mach's notebooks were rather stationary tools. Only a few notes indicate (by topic or by a change in the handwriting) that they were used outside, for example while travelling. Tellingly, two photographs show the notebooks directly within reach at the writing desk. The first was obviously taken in the last years of Mach's life (fig. 1), when Mach lost the use of his right arm after a stroke. The typewriter on the right side of the writing desk (from Mach's perspective) was a model with a full set of capital and lowercase letters that could be run by one hand. Bundles of pages with typewritten notes indicate that he tried to transfer the practice of note-taking to the new medium. ${ }^{6}$ The "old" notebooks - three of them are visible on the left side of the writing desk - were nevertheless still in use. As small slips of paper serving as bookmarks suggest, Mach continued reading in his notes. Although the "active life" of the notebooks had come to an end, their archival function was not affected. Because Mach never indexed single notebooks, nor produced a general inventory, he must have managed to keep track of the content solely by memory (or trial and error). Likewise, no direct evidence exists to suggest that Mach systematically related notes in one notebook to notes in others. Even signs to mark cross-references within one and the same notebook are to my observation - missing.

These details testify to the "unsystematic" approach toward the notebooks. In the recent literature, notebooks and note-keeping practices are very often considered organizational tools (see, for example, te Heesen 2005; Dienel 2006). This holds partly for Mach's notebooks, with the reservation that no particular scheme of organization was introduced. The notebooks were neither kept as diaries (apart from the beginning date, which is noted on the flyleaf, calendar dates appear very rarely and only in conjunction with appointments), nor were they dedicated to particular topics. The notes were simply written one after another from the first to the last page (but because of the general absence of calendar dates, it is in most cases impossible to determine

${ }^{6}$ These typewritten notes are part of the portion of Mach's papers preserved in the Philosophical Archive at the University of Konstanz. 


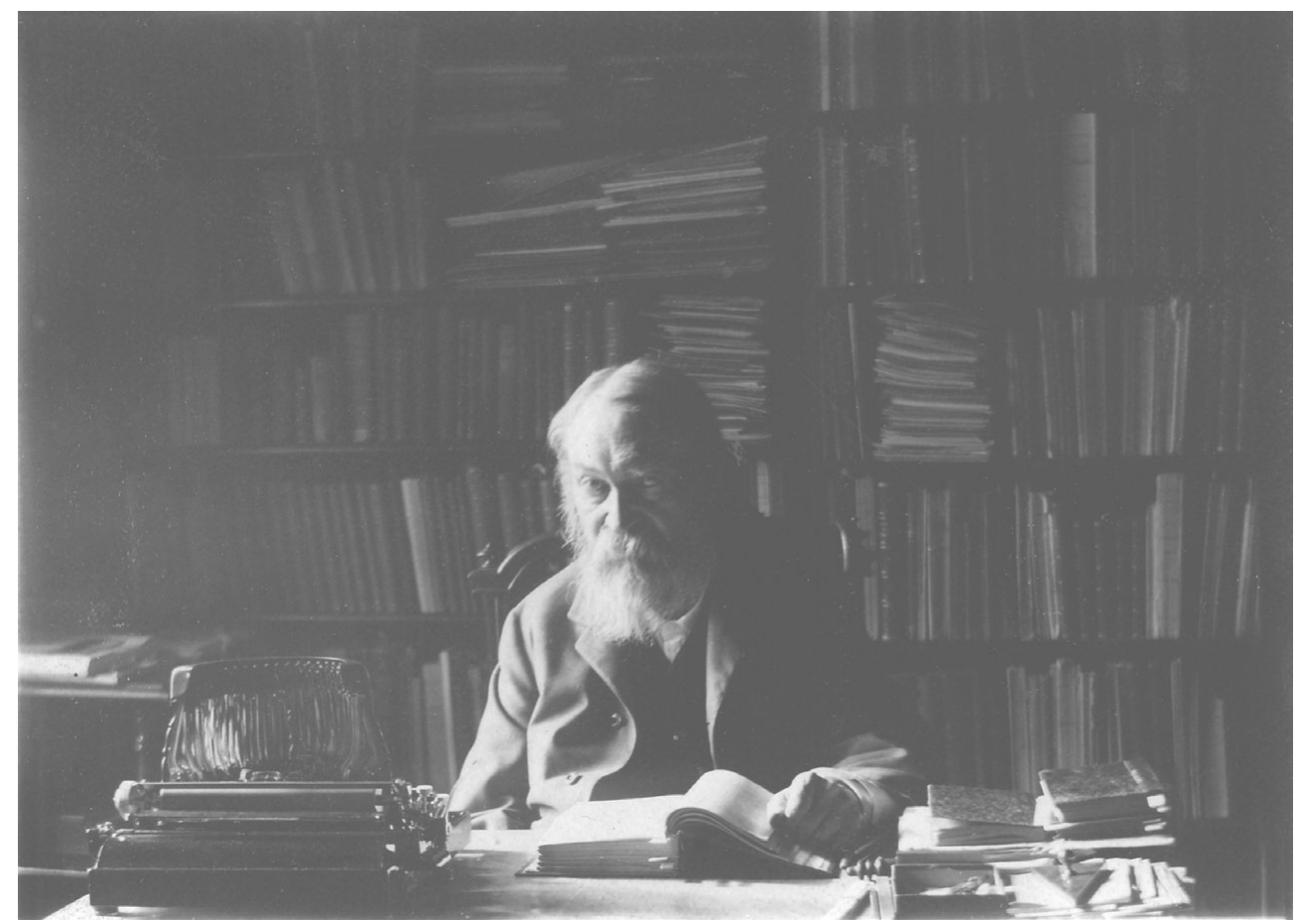

Fig. 1. The philosopher's writing desk, last decade of his life. Reproduced by permission of the Philosophisches Archiv, University of Konstanz; all rights reserved.

the time span between two entries). The pages are filled with writing, sketches, and sometimes with mathematical formulas and calculations. All three types of notes can interact with each other. In fact, in his notebooks Mach very often relied on combinations of drawings and writings. The most astonishing cases are those in which phenomena and concepts from usually strictly separate scientific contexts are conflated in one graphical formation. Mach, who always emphasized the productive power of analogies, apparently developed a genuine technique for producing analogies in this manner (cf. Hoffmann 2003, 192-94).

The photograph of Mach sitting at his writing desk must have been part of a series, probably taken for an official portrait. ${ }^{7}$ The picture presents an image of a philosopher surrounded by his library, studying the book in front of him. The staging clearly reflects the shift in Mach's public recognition since the 1890s when the experimental physicist was increasingly identified as the author of the "The Science of Mechanics" (1883), "Analyses of Sensations" (1886), "Principles of the Theory of Heat" (1896),

\footnotetext{
${ }^{7}$ In many books and articles, a second version of the scene is reprinted, taken from a different angle and this time with the right hand placed on a closed book (for instance Blackmore 1972, between 202 and 203).
} 


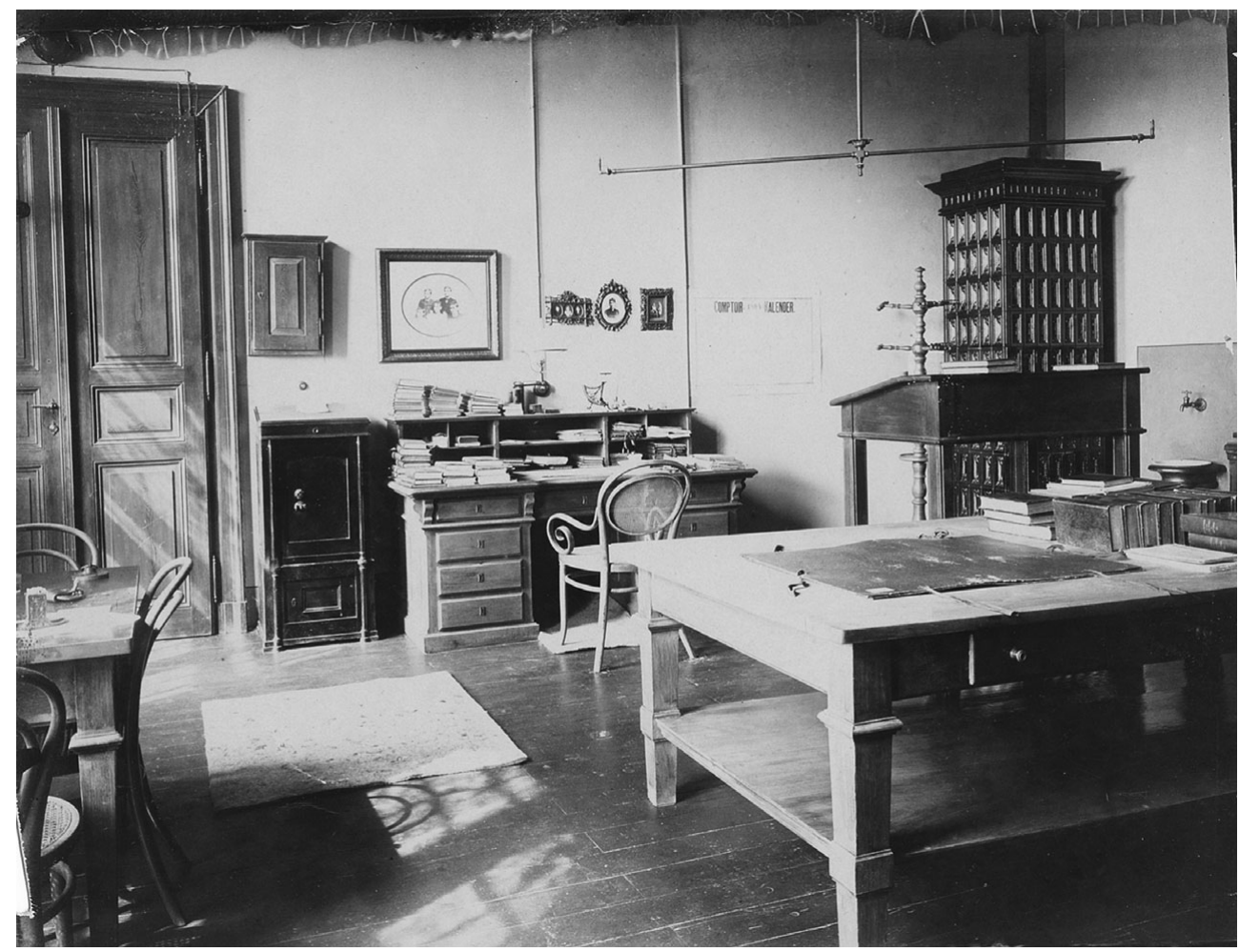

Fig. 2. The writing desk in the laboratory, 1895. Reproduced by permission of the Philosophisches Archiv, University of Konstanz; all rights reserved.

and later of "Knowledge and Error" (1905). However, the practice of note-taking was not considerably affected by the change in role. The "epistemic things" changed; mathematical notations slowly disappeared, and drawings became less frequent. But the general mode of usage and the types of procedures that Mach had developed over the years for posing questions and developing ideas remained remarkably stable. Of particular significance is the near absence of reading notes. This point accords with the one overarching restriction that marks Mach's practice of note-keeping; his notebooks hardly ever contain primary recordings, neither data nor observations directly taken at the bench, nor excerpts from the literature.

A second photograph showing the writing desk in Mach's laboratory in Prague (fig. 2) provides still other clues on the role of note-keeping in his life. All three rooms were arranged along one axis in such a way that one could see straight through from the entrance door (to the left of Mach's writing desk, fig. 2) to the end wall of the rear laboratory. Another photograph of the room with Mach's writing desk also shows a bookshelf and, on the rear wall, installations for students' training. In short, reading, 
teaching, research, and writing all took place more or less within mere footsteps of each other. A closer inspection of Mach's writing desk reveals the portraits of his wife and his children pinned to the wall (which marks this as Mach's writing desk). To the right of the writing desk, a huge office planner from the year 1895 covers the wall (allowing the photograph to be dated). Sitting on top of the writing desk beneath the electric lamp is a letter scale. The piece of furniture to the left of the writing desk appears to be a filing cabinet, the smaller case above it resembling a fuse box or a key box. On its left side, the writing desk itself is covered with books, while the compartments on the right side probably contain loose manuscripts. The description of the various items and details at and in the vicinity of the writing desk confirm that this was indeed the place where everything came together. It may thus come as no surprise that we find Mach's notebooks here as well, three of which are stored to the right of the middle compartment.

In Mach's daily routine note-keeping functioned as an intermedial link. As a rule, almost everything could be noted down on one and the same page. Clues regarding institutional business and research work mingle seamlessly with private affairs like comical verses or a draft of Mach's last will (and many, many more things). Broadly speaking, two general functions of note-keeping can be distinguished. On the one hand, notes helped this researcher, university professor, member of the Imperial Academy, commentator on the educational system, husband, and father of five children (keep in mind the portraits on the wall) to cope with the numerous activities and matters that occupied him. On the other hand, the pages of the notebooks provided space for assembling research plans and experimental set-ups, for evaluating the outcome of laboratory work, as well as for developing and reworking ideas for talks and essays. The tendency for everything to be mixed up on one and the same sheet of paper notwithstanding, the notes frequently focus on a certain issue over the course of several pages. The most intriguing passages are those dealing with open questions. As we will see in the subsequent section, this takes place in a very radical way. To keep notes is not to seek a direct answer; rather, the process of notating primarily aids in exploring, broadening, consolidating, dissecting, and reframing a problem. Those "write-ups" fill in the space of inquiry between the activities at the bench and the final version of a scientific paper to be published (Rheinberger 2003, 624). In this context (and as we will see in purely intellectual activities as well), note-keeping for Mach performs the role of a research tool. The emphasis is on "tool" because the challenge of this article is to discern what, in particular, writing makes possible with respect to the items processed.

\section{Framing the Vague, Demarcating Differences}

In the following, I will relate my general assumptions on writing procedures to two examples from Ernst Mach's notebooks. According to the character of these notebooks 
as space for reworking and organization, the focus is on the use of writing in the context of reasoning and reflecting. One example addresses the role of lists for shaping the theme of a lecture. The other highlights the step-by-step iteration of an open question through a series of notes. The discussion will closely adhere to the sequence of manipulations and the probable effect of the writing procedures in their respective contexts. Information on the broader framework of all these scribbles, notes, catchwords, phrases, and sketches is necessarily more limited. In fact, the paper does not deal with Mach's scientific work or how it becomes accessible through his notebooks. Moreover, the paper does not aim for a coherent account of Mach's writing practices. His notebooks, rather, serve as the basis for an argument about the instrumentality of writing.

Notebook 38 from the year 1895 includes about ten pages of notes that may be identified philologically as the first draft of Mach's inaugural lecture "On the Part Played by Accident in Invention and Discovery" at the University of Vienna in the fall of the same year (Ernst Mach papers, 174/0542, f. 31r-36r; my pagination; the lecture is reprinted in Mach [1896] 1943). ${ }^{8}$ But considering these notes with regard to the final outcome unavoidably implies a teleological perspective toward the material. Every written word is then evaluated either as being part of the later lecture or as having later been discarded. For Mach, in turn, in the very moment of writing the notes, the situation must have been more or less open. It is beyond question that he began taking notes with the looming event already in mind. But the occasion for writing should not be confused with the actual purpose of writing. Simply stating that Mach began developing his lecture with these notes overlooks that he first had to define the topic. Once again, Mach certainly did not grope around in the dark; he did not assemble diverse topics from which he eventually chose one to become the focus of his lecture. Nevertheless, it appears that the relation between the notated items (mainly names of scientists and areas of research, events of discovery, and reflections upon central issues and conditions of discovery and invention) is indeterminate. The assumption, therefore, is that the ten pages of notes were instrumental in detecting or inventing a common thread.

Before the discussion goes into detail, two remarks on the activity of inscription must be made. The first touches upon the relation between notating and producing texts. The notion of "text" is one of the most critical in literary studies. Even the very general definition of a text as a linguistic web in which each unit may be related in a syntactical and/or semantic way owes its persuasive power to the applied metaphor, namely, "web." Perhaps as a consequence of the definition problem, literary scholars tend to include almost every piece of writing under the notion of "text." Yet, heuristically it matters whether writing is acknowledged as a means of text production, i.e. as a

\footnotetext{
${ }^{8}$ The numbering of the notebooks, i.e. notebook 38 here, and later notebook 25 , refers back to the first catalogue of the main portion of Mach's papers in the 1970s. With the transfer of the documents to the Archive of the Deutsches Museum in Munich, all items were renumbered. For reasons of brevity, the old numbering is still used in this paper; the current archival number is given in the reference.
} 
means for giving a definite shape to ideas (however limited and dispersed these ideas may be), or whether writing, as this paper argues, is acknowledged as an instrument for processing items. Likely no one would find it meaningful to subsume a chemical formula under the notion of "text." Notes, too, should not be considered as somehow fragmentary texts, because then they again garner interest mainly with respect to a final result, i.e. the "text" (see, for example, the discussion of scientific note-taking in terms of "multimodal text production") (Wickman 2010, 287).

This leads to the second aspect. If we try to develop an instrumental perspective on notes and the process of inscription, we must be far more explicit about what these terms mean in each particular context. Notes share some general features; they are short, provisional, crude, in linguistic terms: elliptical; and very often notes lack basic syntactic coherence. These features allow us to mark certain traces of writing as notes, but notes differ in the context of their production. We can discern reading notes from listening notes (taken during a lecture, for instance), observational notes from notes in preparation for an event, and in each instance, the inscription is shaped by its circumstances and can serve a different purpose. From a systematic point of view, the terms "noting down," "taking notes," and "keeping notes" denote a particular type of "sheer writing." They do not denote a writing procedure. For example, marginalia (a typical writing procedure) adhere without difficulty to the basic features of notes mentioned above; nevertheless, almost everything that characterizes marginalia is related to the specific sequence of actions that notation follows in this case.

To return to the pages in Mach's notebook 38, there are a number of characteristics of these notes crucial to my argument. The three example pages (figs. 3 and 4 ) show a predominance of catchwords with little to no syntactical coherence. The notes are apparently organized in such a way that a new note (consisting of one catchword or rudimentary catchphrase) is always written in a separate line below the previous note. Taken at a glance, the activity of inscription has resulted here in the production of lists. The fact that the catchwords are placed under several headings (marked by position and underlining) also leads to the same conclusion. In general, the traces of writing resemble more an assemblage of items than a text with gaps. What they mainly have in common is their graphical, spatial definition as elements of a list and thus as items that in Mach's eyes must have belonged to the notion of the heading. Any internal order beyond this seems lacking. There is neither an identifiable ranking (as would be indicated, for example, by a numbering of the items), nor can a sequential logic be identified (in the sense that the location of every item is dependent on the preceding and subsequent note, as in a check-list).

In cognitive terms, Mach was brainstorming here. Yet mental activity relied on material operations. A list is a writing procedure, as becomes patently clear with respect to its oral relative, the enumeration (Mainberger 2003, 5-6). Pure enumerations, without written basis, show little flexibility for reordering because reproducing them relies heavily on mnemonic techniques. Once a number of items has been assembled, each tends to relate to the others in a stable order for reasons of memory. Additional 


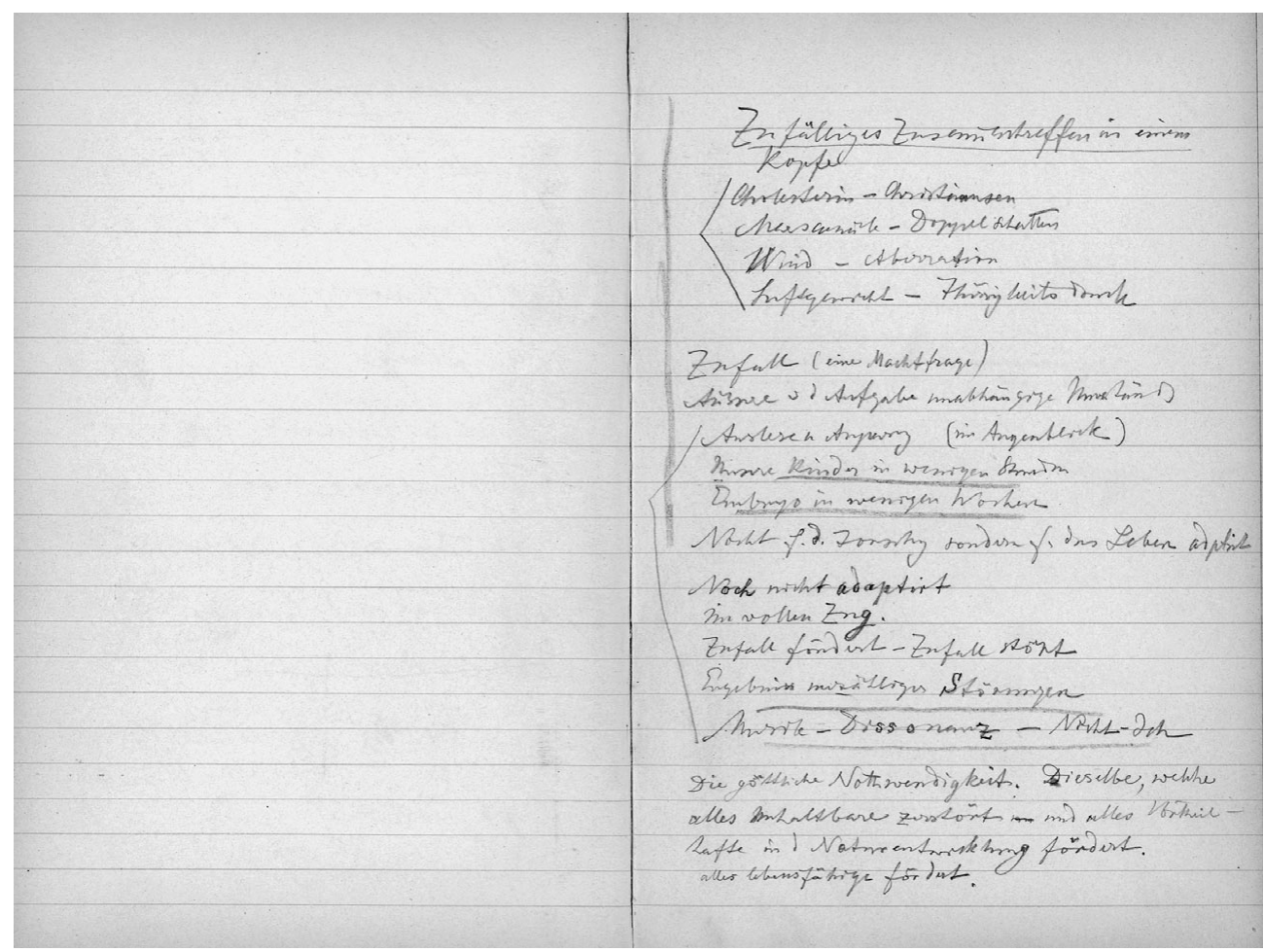

Fig. 3. Notebook 38, Archiv des Deutschen Museums, München, Ernst Mach Papers, NL 174/0542, f. 30v-31r; my pagination.

items may be included, but an entirely new organization seems at the very least an awkward task. The list, in turn, not only preserves ideas from brainstorming as fixed catchwords, but also enables catchwords to be examined in a different way through their placement on the surface of the paper. The temporality of mental activities (one idea after another) is replaced by the spatial simultaneity of written items that may now be related to each other in multifarious ways without being limited by the ongoing stream of thought and the capacity of the human memory. Indeed, the first effect of "listing" thus consists in the exteriorization of the contents of the mind (cf. Krämer 2005). It is the "particular distance" (Kogge 2005, 165) between observer and surface of the page that here enables a mode of exploration.

A list, however, creates a spatial arrangement that in almost every case paves the way for future actions. ${ }^{9}$ Not only can lists bear upon the future in the sense of Goody's

\footnotetext{
${ }^{9}$ On list making as part of research operations (mainly in the context of natural history), see also very recently (December 2012) the focus "Listmania," in ISIS 103(4). Unfortunately the contributions were published too late to be considered in my argument.
} 


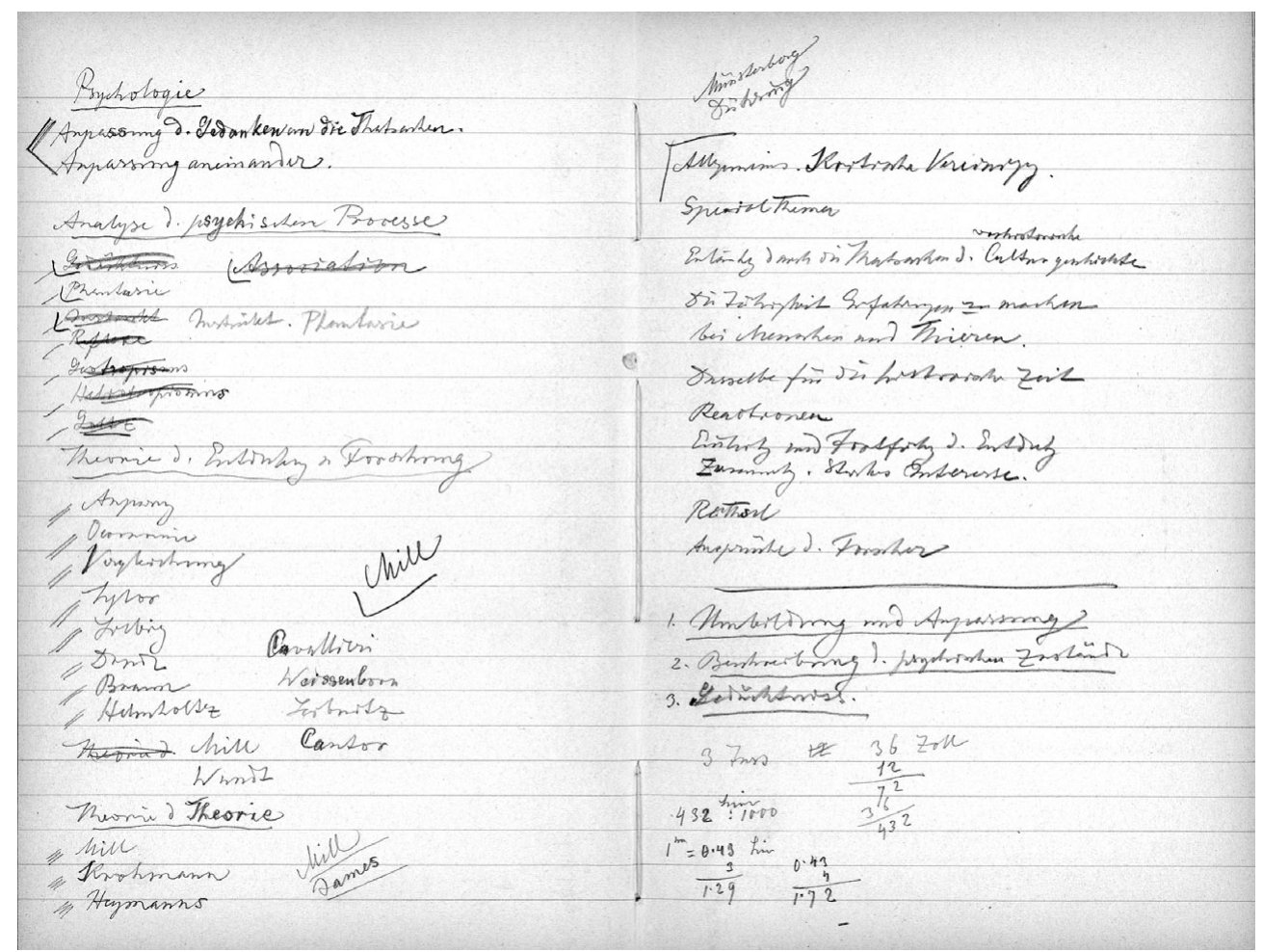

Fig. 4. Notebook 38, Archiv des Deutschen Museums, München, Ernst Mach Papers, NL 174/0542, f. 35v-36r; my pagination.

"prospective lists" (Goody 1977, 87), but as part of the procedure, they also inherently suggest the further reworking of the listed items. As a ubiquitous type of "prospective list," the shopping list, for example, also implies, with the future act of shopping, the future crossing-out of the listed goods (or at least a verifying glance as to whether all listed goods have been obtained). The same is true for "retrospective lists" (ibid., 80), which deal with the past. The lists in Mach's notebook 38 represent, in fact, a mixture of retrospective and prospective elements. They preserve ideas that come to mind, but once listed, each idea might stimulate new ideas and relations and might result in the addition of further items to the list or in a regrouping of the listed items. In our case, this actually happened. Together, the numerous brackets, underlines, marginal markings, and additions testify to a process of reworking that both intensifies and disperses the original arrangement of the items. Some are more closely linked with each other (brackets), which "distances" those items nearby that were not included. Some items may prove central (underlines) while "debasing" those that are not highlighted. And other items inspired new elements (additions), testifying to the "incompleteness" of the original list. 
What becomes visible here is the activity of relating, expanding, reordering, and excluding, which is already encapsulated in the spatial procedure "listing." In fact, the "list" consists of two procedures: a spatial one that manifests a graphical arrangement, and a temporal one that manifests a sequence of actions (first listing, then marking). The intermediary step, reading, is therefore an extension of writing. The marks resulting from the reading process resemble operators (like mathematical signs) that contain instructions for further action. The procedure "list" can, of course, serve a wide range of purposes, and Mach's notebooks provide examples for all sorts of lists. But in this particular context, Mach used the list - in Heidegger's sense - as a means of “concretion." Robert E. Belknap's observation that "connections between elements in a list may be readily apparent or vague and indistinct" (Belknap 2004, 3), can thus be rephrased even more radically. Sometimes, as in our case, the process of listing does not follow prior connections between items, but rather explores possible connections. Even the catchwords that serve as headings do not guarantee that the assembled items really belong to one group. In fact, only within the process of noting down, arranging, marking, and relating items does the prospective area of interest take shape as an array of concepts, names of scientists, and episodes from the history of science.

This process should not be confused with the simple clarification and development of an originally vague idea. Rather, Mach's lists give contours to vagueness and thus facilitate later editing that could transform or negate some of the preliminary ideas as well. A crude arrangement of "themes" on the tenth and final page of notes is instructive (fig. 4; Ernst Mach papers, 174/0542, f. 36r; my pagination). With respect to subjects and sequence, it partly resembles the final character of Mach's lecture. But none of those "themes" coincides directly with any of the headings of the lists that Mach had noted on the previous pages. Obviously, the procedure of listing and marking led Mach to an organization of his ideas that he had not envisioned when he began the process.

In my second example, a very similar challenge is linked to a different type of writing procedure. Mach's notebook 25 contains several pages of notes (roughly datable to the first few months of the year 1887) dedicated, according to the first note, to the "relation of stationary current to the propagation of sound [Beziehung der stationären Strömung zur Schallfortpflanzung]" (Ernst Mach papers, NL 174/0529, f. 46v-51v, quotation f. $46 \mathrm{v}$; my pagination). With some background knowledge, it is easy to recognize that Mach struggled here with a theoretical approach to his studies of ballistic phenomena (today known as one of the origins of supersonic aerodynamics). In the following, my discussion addresses the function of writing in refining the aforementioned relationship "of stationary current to the propagation of sound" (figs. 5 and 6). This relation was not at all settled in those days. On the contrary, Mach's studies (carried out together with the physicist Peter Salcher in the course of 1886) were the first to reflect empirically upon this issue through experiments and observations (for the epistemological "landscape" in which these studies are located, see Hoffmann and Berz 2001). 


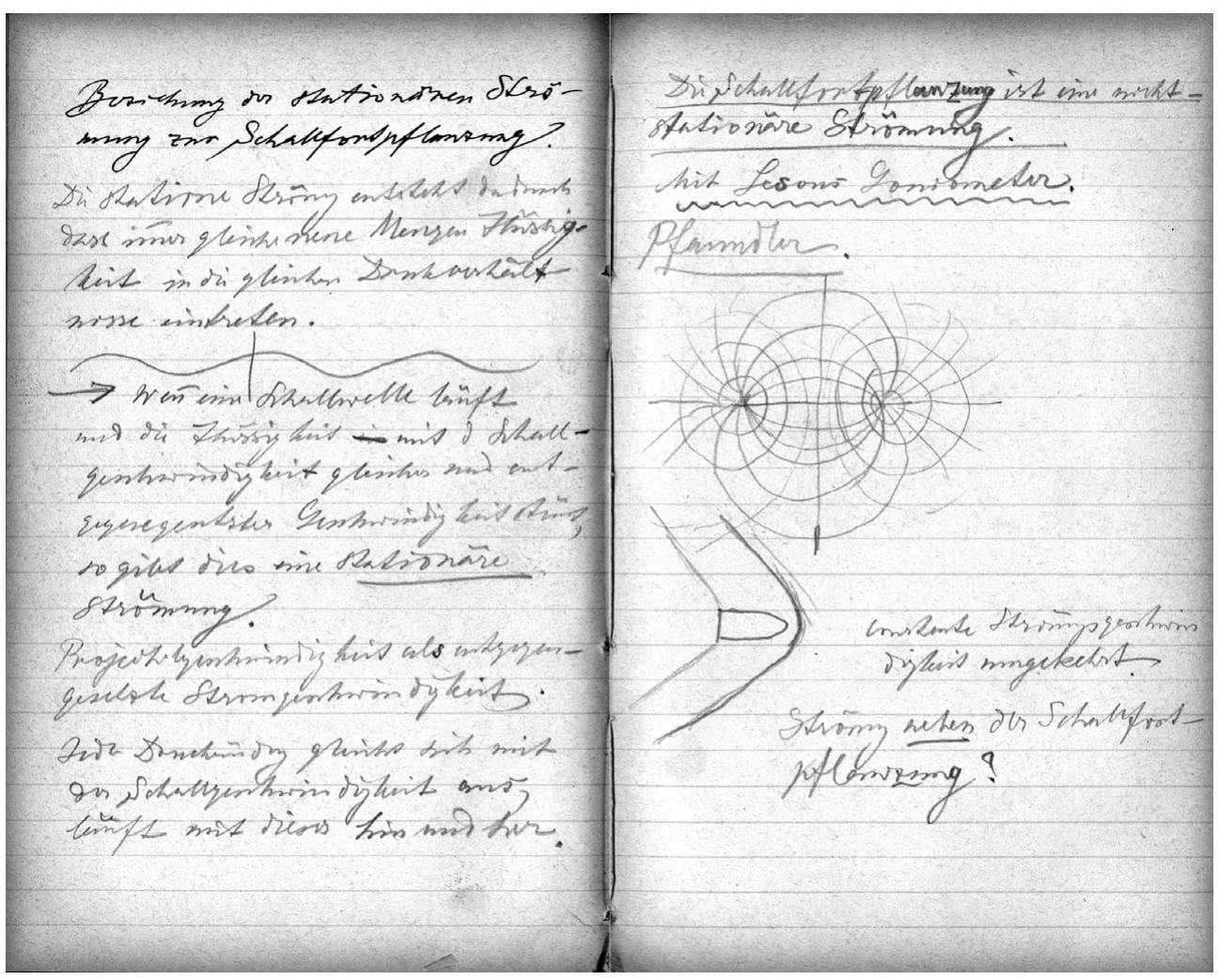

Fig. 5. Notebook 25, Archiv des Deutschen Museums, München, Ernst Mach Papers, NL 174/0529, f. 46v-47r; my pagination.

The notes comprise complete phrases and catchwords, sketches, and some formulas. All these notes seem to interact either insofar as catchwords and phrases comment on the sketches (or vice versa), or in that formulas develop aspects of the sketches and written notes (or vice versa). Direct graphical links between the notes are absent, apart from the first of the reproduced pages (fig. 5, on the left) where a sketch of a sound wave is related by an arrow to the subsequent written comment. In fact, one hallmark of the notes is the absence of nearly all indications of internal correlation. Only the repetition of the words "sound," "sound wave," "stationary," "current," and some other related terms justify the determination of the notes as a single series devoted to one and the same challenge.

The absence of any comprehensive structural organization implies two ideas. Firstly, the notes were not the outcome of a prior plan. They did not provide answers to a series of fully formed questions Mach had in mind prior to writing, sketching, and calculating. Secondly, and connected to this, the notes were not written in one continuous act. The later idea is doubtless highly speculative because, as mentioned above, Mach's 


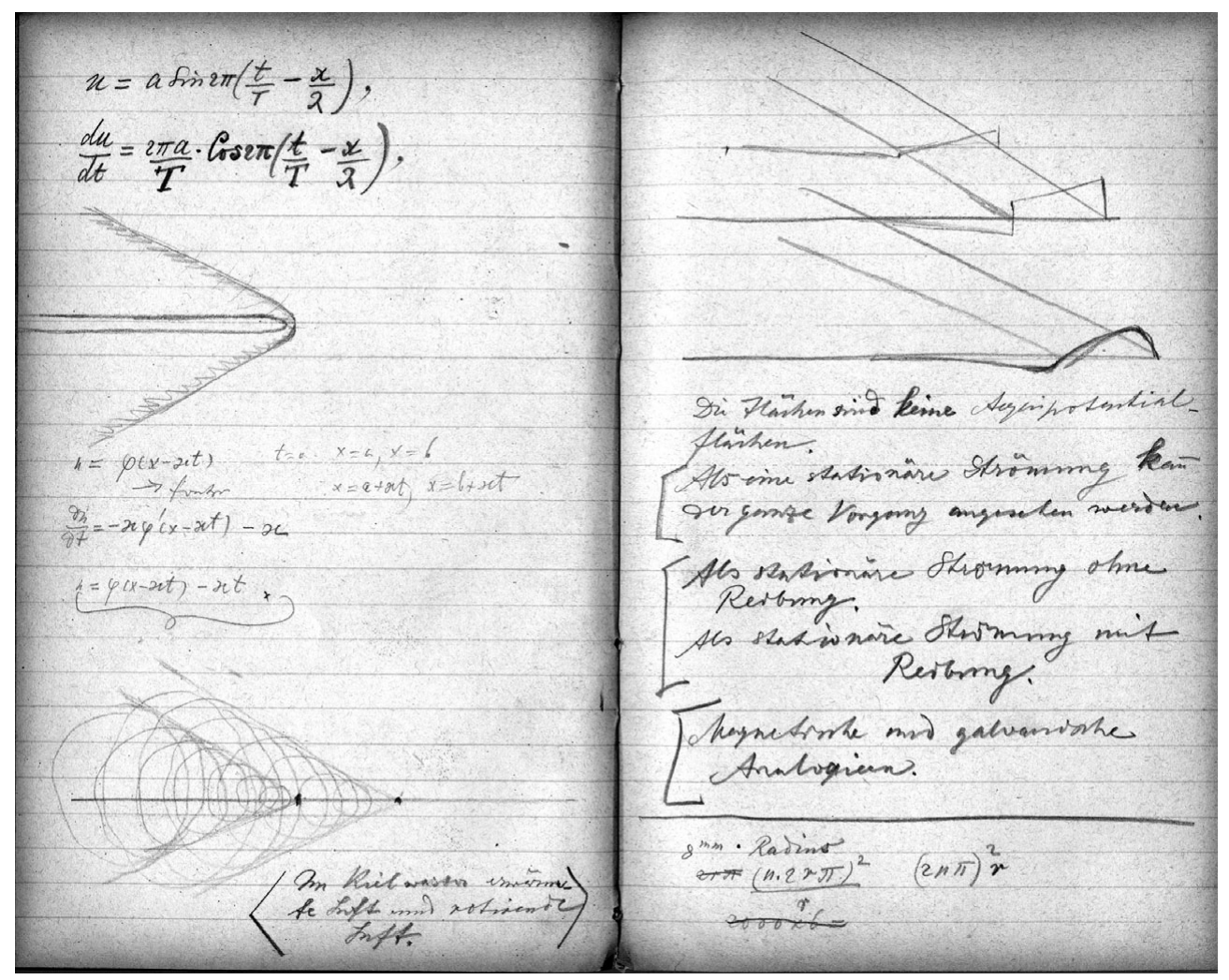

Fig. 6. Notebook 25, Archiv des Deutschen Museums, München, Ernst Mach Papers, NL 174/0529, f. 47v-48r; my pagination.

notebooks rarely indicate the time span that elapsed between two notes. The following argument, however, does not focus on the exact increment of time that might separate one note from the next. It addresses the peculiar procedure of inscription. Consider, for example, the first two pages (fig. 5): the initial entry is followed by notes that define the conditions of stationary currents and sound propagation. Then, the speed of the projectile is introduced as a new aspect. Afterward, the propagation of sound is characterized as a non-stationary current (in the form of a statement). The notations then transform into a sketch followed by the phrase: "constant current velocity inverted [constante Strömungsgeschwindigkeit umgekehrt]," and below this comment the question follows: "current alongside the propagation of sound [Strömung neben der Schallfortpflanzung]?” (Ernst Mach papers, NL 174/0529, f. 47r; my pagination).

What takes place in the course of writing may be classified as a kind of shifting. Each note apparently reacts to the preceding note, either further varying what has been noted (in the double sense of notating and becoming aware; cf. Daston 2004, 
445), taking an opposing tack, or adding new aspects like the (from today's point of view) peculiar idea that the "[air] current" and the "propagation of sound" could coexist as separate processes at the same time. The hypothesis that the notes were not written in one continuous act may now be qualified to say that the notes were written in a sequential manner. The first entry establishes a certain aspect, then the same note triggers one more aspect that is written down, sketched, or put into a formula in the subsequent note. The common saying that one thing leads to another very well describes the process at work; the procession relies on the temporal arrangement of noting down, inspecting the inscriptions, and inscribing the subsequent note. In this particular case, the historicity of the writing process is crucial and may itself be considered procedure-like. As Luhmann has put it with respect to the legal system, a procedure translates into a history of decisions. "In light of what is already fixed, that which is still undetermined is interpreted and further narrowed [Im Licht des schon Feststehenden wird das noch Offene interpretiert und weiter eingeengt]" (Luhmann [1975] 1983, 44). Rephrased in a less progressive manner: with each item that has been noted down, a new situation is created from which the next entry takes shape on the surface of the page.

A critical evaluation of the argument may lead to the objection that the "sequential nature" of the notes might be partly the result of my description, and furthermore that a minimal knowledge of the noted subjects is already a prerequisite for discerning the "reactions" of a note to the preceding one. However, this paper did not claim that writing procedures must be reconstructed without any relation to the meaning of what is written. The concepts from hydrodynamics and acoustics and the various results of Mach's and Salcher's experiments that come into play here were disregarded only for heuristic reasons. Instead of attempting to integrate the notes directly into a conclusive narrative (and thereby adding a "teleology" that eliminates the prior dynamic of the process), the task was to isolate the procedural mechanism and its contribution to the evolution of aspects. Again, the second example documents how, at their root, thought processes are dependent on and driven by the procedural use of writing. But in contrast to the first example, the process here engenders discrepancies more than it does consistent relations. The statement that a sound wave is a non-stationary current need not be classified as an awkward reformulation of an otherwise well-defined physical phenomenon. Rather, it spells out a particular difference between the phenomena that Mach observed in the air around the projectile and the regular behavior of a sound wave. In one sentence: with the adopted procedure, characteristic differences between the two initially related items - "stationary current" and "propagation of sound" - gradually take shape (which is, in turn, the precondition for developing their relation in a more refined way later on). The writing procedure does not lead to the desired relation, but indicates further directions of inquiry. In Heidegger's terminology, through the procedure the prospect of inquiry is reshaped.

A summary of the two examples of writing procedures from Mach's notebooks shows some common points. Most obviously, they document how objects of inquiry 
- the topic of a lecture and the relationship between two phenomena - are elaborated through the spatial order of the written traces and the temporal sequence of the writing process. To varying degrees, the instrumentality of writing as a research tool always relies on these two main aspects. The two examples also share the use of writing procedures as means of reflection. This limitation is due to the function of the notebooks in Mach's workspace. As an "intermedial link," the writing processes in the notebooks mainly engage in mediating tasks. They tie together and organize the divergent spheres of Mach's life and - to allude to the title of Latour's paper "Drawing Things Together" they write things together. In contrast to Latour's occasionally too linear, smooth notion of "paperwork," however, the examples here underline that writing procedures can result in more complexity (namely in the second example: in additional distinctions), or even in the transgression of the original organization of the items (as the replacement of the very provisional list headings by a still very crude schematic arrangement in the first example). Nevertheless, it is hard to show in detail what the particular writing procedure prompted in the particular context of the two examples. Although the traces on the surface of the paper point to a regular procedural course of action, it remains speculation to attribute directly to the writing process certain turns in the understanding of a problem or shifts in the outline of a lecture. To do this, moreover, would negate the fact that writing procedures merely offer a framework for processing items. As "technical objects" they are crucial for "entrenching" and "articulating" the "epistemic object" (Rheinberger 1997, 29). They may develop a dynamic of their own and potentially enable the emergence of relationships or aspects that had previously gone unnoticed, but they cannot and do not determine the outcome of the whole process.

Finally, the second example clearly differs from the first in one regard. The production of a list is a well-known, transculturally shared, everyday practice with a long history going back to the beginnings of writing in Mesopotamian cultures. The process of iteration through inscription that was discussed in the second example does not correspond very well with these characteristics. The procedure lacks a particular name, indicating that the practice remains below the threshold of common intersubjective usage. Furthermore, one may doubt whether the procedure is consciously applied at all. I admitted above that a writing procedure is very much context-sensitive and, so to speak, individualized through its use, but a minimal awareness of its usage seems necessary. Otherwise, we must imagine that the iterative process can take place without any intention. Indeed, with the second example we might arrive at a most far-fetched notion of a writing procedure.

\section{Conclusion}

A close study of only a few pages from one scientist's notebooks from the late nineteenth century almost automatically raises the issue of generalization. How representative are 
these sample cases? First of all, it is obvious that writing in the sciences fulfills many more functions and has more ramifications than this paper was able to explore. Recording experiments or noting observations, for instance, raise very different questions. What does the recording process retain and lose? What kind of instructional or formal regulations come into play? How much is the process of recording already shaped by subsequent steps of processing? To what extent does the procedure of recording direct the researcher's attention? What kind of restrictions result from the research sites and the objects of inquiry? Likewise, we must consider the historicity of writing procedures and their probable relation to certain writing materials. Can we admit that Mach's practice of inscription is related to the particular organization of academic teaching and research? Is it more than coincidental that the series of notebooks started with his new position as director of an institute? Is there any common thread in the use of notebooks in the context of science aside from very general features? Do writing procedures vary only with respect to context and individual preferences, or do they have a history of their own? Has the procedure of listing substantially changed over time? Is there any procedural difference between a list inscribed in clay and a list written on paper? Does computer use create new parameters? Is Mach's practice bound to a cardboard and paper "notebook"?

Notwithstanding all these questions, one perspective on the issue of generalization might be that the listing procedure in Mach's notebook 38 could probably be taken as representative for one very common type of process on paper, whereas the notation procedure in notebook 25 seems far more to be an idiosyncrasy of Mach's. At second glance, however, "generalization" might be the wrong category with respect to procedures. If Heidegger is right that every procedure - as a means of concretion - is shaped only through the process of inquiry and in relation to the object of research, then procedures never can be generalized. Procedures in the strong sense must remain singularities exactly because it is their intrinsic character and the core of their utility that they adapt to the specific context in which they are applied. The answer is then twofold; on the level of the identified procedures, the individual characteristics and the local circumstances limit any transfer of conclusions from one set of papers to another. But on the more abstract level of the systematic approach, case studies like the one developed in this paper may very well provide clues to the ways writing can be instrumental. The discussion of the two sets of pages from Mach's notebooks demonstrates by example how such materials can become a positive object of inquiry, without merely complaining of their shortcomings. Attention to the spatial arrangement of the inscriptions and to the temporal sequence of actions provides an analytical perspective that may help identify what kind of questions must be addressed. Cultivating the notion of writing procedures might suggest how to showcase the sometimes remarkably sophisticated uses of writing in the context of scientific research. Considered as a process-oriented device, writing loses many of its usually presupposed, supplementary features. In fact, one aim of this paper was to illustrate that writing (not only) in science may not be reduced to its archival function alone. 
The last point places the approach of the paper in a context beyond history of science and the study of scientific practice in general. Many of my observations and conclusions might appear very familiar to researchers who study writing processes empirically from the angle of cognitive psychology. Carl Bereiter's notion of "epistemic writing," through which writing "becomes an integral part of thought" (Bereiter 1980, 87-88), and Donald M. Murray's emphasis on the crucial role of "revision" as a means of discovering "meaning through writing" (Murray 1978, 87) - both from classic papers in their fields - can, at first glance, be easily adapted to Mach's writing practice and the related argument on the tool-character of writing in scientific research. Without going into the details of the vast literature on this research field, I see, however, two basic differences to the approach developed in this paper. In most empirical studies, the process of writing is identified with the production of a text (cf. only Alamargot and Chanquoy 2001). As already emphasized with respect to notes (see above, section IV), this assumption is in many cases invalid. Because of the identification with text production, the process of writing takes shape as defined by its prospective end: first planning, then translating, and finally revising (cf. the widely shared model of Hayes and Flowers 1980 and Bereiter and Scardamalia 1987 differ mainly with respect to the emphasis put on the emergence of structure in the process of writing; for a recent review of models, see McCutchen, Teske, and Bankston 2008). The overall idea is then that writing (loops granted) leads from a defined starting point to a definite closure, whereas the examples from Mach's notebooks indicate that on the micro level, writing processes instead incite discontinuities, increasing complexity, and, all in all, new problems and questions. The second crucial difference in my eyes is related to the status of writing. From a cognitivist point of view, writing appears as the extension of mental activities. To put it bluntly: studies of this kind do not conceive of writing on its own. When they analyze writing processes, they ultimately evaluate written traces as marks of mental processes. This becomes very clear from the fact that the writing process is subdivided into types of cognitive operations (see above: planning, translating, revising). How writing actually takes place, which graphical operations come into play each time, what kinds of regularities they show, and, most important, what sort of actions and effects writing enables are, in turn, almost always neglected. Statements like Bereiter's above constitute little more than proclamations. No one doubts that writing is "an integral part of thought." The challenging point is to show how writing practically assists mental activities.

The last matter may be traced back to the 1960s and the discussion about the impact of writing, and particularly of the Greek alphabet, on the emergence of Western thought and culture (Goody and Watt 1963; Havelock 1963). A more modest version of the argument could rely on Pierre Bourdieu's observation that in the social sciences the graphical means of "objectivation," i.e. the graphical display and organization of "data," in some respect tend to rectify the probable object of inquiry (Bourdieu [1980] 1990, 11). His observation that temporal processes are made linear by their inclusion in synopses and tables (ibid., 82-84) justifies the assumption that implementing a writing 
procedure always activates a style of reasoning as well. For instance, the procedure "list" (i.e. listing and marking) can, of course, serve a wide range of purposes. But at their core, lists like tables are "relative" tools. They induce first and foremost the processing of "matters" as related items. Accordingly, the usage of lists potentially results in a world picture full of interrelations and hierarchies. Under this condition, it seems that writing not only assists mental activities, but also might even direct and shape cognitive processes. If we accept this conclusion, we must concede to writing a certain autonomy. Without a doubt, writing always involves mental activities, but the fact that we know how to produce a list, for instance, should not be confused with what the procedure "listing" accomplishes and affects. In fact, this paper ultimately addresses one simple point, namely: what characterizes writing not related to the subject (the writer), not related to what is written (the context) - which is to say: what characterizes writing taken alone? This question was once posed in its basic form in Jacques Derrida's critique of "phonocentrism," i.e. the fundamental reduction in the understanding of writing by discussing it with concepts of speech. As we know, Derrida's answer focused very much on the trace and the ongoing process of supplementation. Today, we find new approaches that more practically attempt to elucidate the operational aspect of writing (cf. Krämer 2005; for a very recent example of this approach related to the manuscripts of Charles Sanders Peirce, see Meyer-Krahmer 2012). The notion of writing procedures contributes to this effort and simultaneously facilitates even more "concretion" in discussing the respective qualities of writing.

\section{Acknowledgments}

The research related to this paper was carried out at the Max-Planck-Institute for the History of Science, Department III. Daniel Bowles cared for the language editing. Last but not least I am very grateful to two anonymous referees for their helpful comments.

\section{References}

Alamargot, Denis, and Lucile Chanquoy. 2001. Through the Models of Writing. Dordrecht, Boston, London: Kluwer Academic Publishers.

Barberousse, Annouk. 2003. "Desiner, Calculer, Transmettre. Écriture et Création scientifique chez Pierre-Gilles de Gennes." Genesis 20:145-62.

Belknap, Robert E. 2004. The List: The Uses and Pleasures of Cataloguing. New Haven and London: Yale University Press.

Bereiter, Carl. 1980. "Development in Writing." In Cognitive Processes in Writing, edited by Lee W. Gregg and Erwin R. Steinberg, 73-93. Hillsdale NJ: Lawrence Earlbaum Associates.

Bereiter, Carl, and Marlene Scardamalia. 1987. The Psychology of Written Composition. Hillsdale NJ, London: Lawrence Earlbaum.

Blackmore, John Thomas. 1972. Ernst Mach: His Life, Work, and Influence. Berkeley: University of California Press. 
Bourdieu, Pierre. [1980] 1990. The Logic of Practice. Translated by Richard Nice. Cambridge: Polity Press. Campe, Rüdiger. 1991. "Die Schreibszene. Schreiben.” In Paradoxien, Dissonanzen, Zusammenbrüche. Situationen offener Epistemologie, edited by Hans Ulrich Gumbrecht and K. Ludwig Pfeifer, 759-71. Frankfurt am Main: Suhrkamp Wissenschaft.

Daston, Lorraine. 2004. "Taking Note(s)." Isis 95:443-48.

Dienel, Hans-Liudger. 2006. "Schreiben, Zeichnen, Erinnern. Persönliches Wissensmanagement im Ingenieurberuf seit 1850." In Technografie. Zur Mikrosoziologie der Technik, edited by Werner Rammert and Cornelius Schübel, 397-424. Frankfurt am Main, New York: Campus Verlag.

Droysen, Johann Gustav. [1857] 1977. Historik. Rekonstruktion der ersten vollständigen Fassung der Vorlesungen (1857), Grundriß der Historik in der ersten handschriftlichen (1857/58) und in der letzten gedruckten Fassung (1882), edited by Peter Leyh. Stuttgart-Bad Cannstatt: Verlag Frommann-Holzboog.

Engstrom, Eric J. 2003. Clinical Psychiatry in Imperial Germany: A History of Psychiatric Practice. Ithaca: Cornell University Press.

Galison, Peter. 2000. "The Suppressed Drawing: Paul Dirac's Hidden Geometry.” Representations 72:14566.

Gooding, David. 1992. “The Procedural Turn; or, Why Do Thought Experiments Work?” In Cognitive Models of Science, edited by Ronald N. Giere, 44-76. Minneapolis: University of Minnesota Press.

Goody, Jack. 1977. The Domestication of the Savage Mind. Cambridge, New York: Cambridge University Press.

Goody, Jack, and Ian Watt. 1963. "The Consequences of Literacy." Comparative Studies in Society and History 5:304-45.

Havelock, Eric A. 1963. Preface To Plato: A History of the Greek Mind. Cambridge MA, London: Belknap Press of Harvard University Press.

Hayes, John R., and Linda S. Flowers. 1980. "Identifying the Organization of Writing Processes." In Cognitive Processes in Writing, edited by Lee W. Gregg and Erwin R. Steinberg, 3-30. Hillsdale NJ: Lawrence Earlbaum.

Heidegger, Martin. [1938] 1977. "Die Zeit des Weltbildes." In Gesamtausgabe. I. Abteilung, Vol. 5: Holzwege, edited by Friedrich-Wilhelm von Herrmann, 75-113. Frankfurt am Main: Verlag Vittorio Klostermann.

Heidegger, Martin. [1938] 2009. "The Age of the World Picture.” In The Heidegger Reader, edited by Günter Figal, translated by Jerome Feith, 207-23. Bloomington: Indiana University Press.

Hoffmann, Christoph. 2003. "The Pocket Schedule. Note-taking as Research Technique: Ernst Mach's Ballistic-Photographic Experiments." In Reworking the Bench: Research Notebooks in the History of Science, edited by Frederic Lawrence Holmes, Jürgen Renn, and Hans-Jörg Rheinberger, 183-202. Dordrecht, Boston, London: Kluwer.

Hoffmann, Christoph. 2008. "Schneiden und Schreiben. Das Sektionsprotokoll in der Pathologie um 1900." In Daten sichern. Schreiben und Zeichnen als Verfahren der Aufzeichnung, edited by Christoph Hoffmann, 153-96. Zurich, Berlin: Diaphanes.

Hoffmann, Christoph. 2010. "Umgebungen. Über Ort und Materialität von Ernst Machs Notizbüchern." In Portable Media. Schreibszenen in Bewegung zwischen Peripatetik und Mobiltelefon, edited by Martin Stingelin, and Matthias Thiele, 89-107. Munich: Wilhelm Fink.

Hoffmann, Christoph, and Peter Berz, eds. 2001. Über Schall. Ernst Machs und Peter Salchers Geschoßfotografien. Göttingen: Wallstein Verlag.

Holmes, Frederic Lawrence. 2004. Investigative Pathways: Patterns and Stages in the Careers of Experimental Scientists. With an afterword by Jed Z. Buchwald. New Haven: Yale University Press.

Holmes, Frederic Lawrence, Jürgen Renn, and Hans-Jörg Rheinberger, eds. 2003. Reworking the Bench: Research Notebooks in the History of Science. Dordrecht, Boston, London: Kluwer Academic Publishers.

Kaiser, David. 2005. Drawing Theories Apart: The Dispersion of Feynman Diagrams in Postwar Physics. Chicago, London: University of Chicago Press.

Klein, Ursula. 2001. "Paper Tools in Experimental Cultures - The Case of Berzelian Formulas." Studies in History and Philosophy of Science 32:265-312. 
Kogge, Werner. 2005. "Erschriebene Denkräume. Grammatologie in der Perspektive einer Philosophie der Praxis." In Schrift. Kulturtechnik zwischen Auge, Hand und Maschine, edited by Gernot Grube, Werner Kogge, and Sybille Krämer, 137-69. Munich: Wilhelm Fink Verlag.

Krämer, Sybille. 2005. "Operationsraum Schrift: Über einen Perspektivenwechsel in der Betrachtung der Schrift." In Schrift. Kulturtechnik zwischen Auge, Hand und Maschine, edited by Gernot Grube, Werner Kogge, and Sybille Krämer, 23-57. Munich: Wilhelm Fink Verlag.

Latour, Bruno. 1990. "Drawing Things Together." In Representation in Scientific Practice, edited by Michael Lynch, and Steve Woolgar, 19-68. Cambridge MA, London: MIT Press.

Luhmann, Niklas. [1975] 1983. Legitimation durch Verfahren. Frankfurt am Main: Suhrkamp Verlag.

Lynch, Michael. 1985. Art and Artifact in Laboratory Science: A Study of Shop Work and Shop Talk in a Research Laboratory. London, Boston: Routledge \& Kegan Paul.

Mach, Ernst. [1896] 1943. "On the Part Played by Accident in Invention and Discovery.” In idem Popular Scientific Lectures, 5th edition, 259-81. La Salle IL: Open Court.

Mainberger, Sabine. 2003. Die Kunst des Aufzählens. Elemente zu einer Poetik des Enumerativen. Berlin, New York: Walter de Gruyter.

McCutchen, Deborah, Paul Teske, and Catherine Bankston. 2008. "Writing and Cognition: Implications of the Cognitive Architecture for Learning to Write and Writing to Learn." In Handbook of Research on Writing: History, Society, School, Individual, Text, edited by Charles Bazerman, 451-70. New York, London: Lawrence Erlbaum Associates.

Meyer-Krahmer, Benjamin. 2012. "My Brain Is Localized in my Inkstand. Zur graphischen Praxis von Charles Sanders Peirce." In Schriftbildlichkeit. Wahrnehmbarkeit, Materialität und Operativität von Notationen, edited by Sybille Krämer, Eva Cancik-Kirschbaum, and Rainer Totzke, 401-14, Berlin: Akademie Verlag.

Murray, Donald M. 1978. "Internal Revision: A Process of Discovery." In Research on Composing. Points of Departure, edited by Charles R. Cooper, and Lee Odell, 85-103. Urbana IL: National Council of Teachers of English.

Nasim, Omar. 2010. “Observation, Working Images and Procedure: The 'Great Spiral' in Lord Rosse's Astronomical Record Books and Beyond.” British Journal for the History of Science 44:353-89.

Rheinberger, Hans-Jörg. 1997. Toward a History of Epistemic Things: Synthesizing Proteins in the Test Tube. Stanford CA: Stanford University Press.

Rheinberger, Hans-Jörg. 2003. "Scrips and Scribbles.” Modern Language Notes 118:623-36.

Rheinberger, Hans-Jörg. [2007] 2010. On Historicizing Epistemology, translated by David Fernbach. Stanford CA: Stanford University Press.

te Heesen, Anke. 2005. "The Notebook: A Paper Technology." In Making Things Public. Atmospheres of Democracy, edited by Bruno Latour, and Peter Weibel, 582-89. Cambridge MA, London: MIT Press.

te Heesen, Anke. 2006. Der Zeitungsausschnitt. Ein Papierobjekt der Moderne. Frankfurt am Main: Fischer Taschenbuchverlag.

Weber, Matthias M., and Eric J. Engstrom. 1997. "Kraepelin's 'Diagnostic Cards': The Confluence of Clinical Research and Preconceived Categories." History of Psychiatry 8:375-85.

Welfelé, Odile. 1998-99. "Organiser le désordre. Usages du cahier de laboratoire en physique contemporaine.” Alliage 37-38:25-41. 